\title{
Perspectivas da Tradição Romanística: passado e futuro do Direito Romano ${ }^{1}$
}

\author{
Perspectives on the Roman Law Tradition: past and future of Roman Law
}

Walter Guandalini Jr.

Universidade Federal do Paraná, Curitiba - PR, Brasil

Resumo: o presente artigo pretende traçar um panorama histórico da tradição romanística ocidental, avaliando os sentidos atribuídos ao direito romano clássico nos diversos momentos em que o saber jurídico the deu nova vida. Conclui com um diagnóstico da crise pela qual passa a tradição romanística no presente, apontando a retomada histórica do direito romano como a saída possível.

Palavras-chave: Direito Romano. História do Direito. Tradição Romanística.

\begin{abstract}
: this paper outlines a historical overview of western romanistic tradition, evaluating the meanings attributed to Classical Roman Law on the different periods in which legal knowledge revitalized it. The article concludes by diagnosing the crisis faced by romanistic tradition nowadays, suggesting its historical recovery as the only way out of it.
\end{abstract}

Keywords: Roman Law. Legal History. Roman Law Tradition.

\section{Introdução}

O direito criado pelos romanos, elaborado como aparato regulador altamente especializado, foi o único modelo da Antiguidade a se afirmar como tecnologia social com estatuto forte, isolando-se de qualquer outra produção cultural ou centro institucional de disciplinamento social (reli-

Trata-se de versão ampliada de palestra proferida no IV Encuentro del Instituto Latinoamericano de Historia del Derecho, ocorrido em Buenos Aires, nos dias 12 a 14 de junho de 2013.

Recebido em: $18 / 02 / 2015$

Revisado em: 06/04/2015

Aprovado em: 11/04/2015 
gião, moral, política) - como não foram capazes de fazer os gregos, hebreus, chineses ou hindus. Esse isolamento formalista permitiu ao direito obter uma identificação autônoma, clara e definitiva, que deixou a sua marca na constituição da civilização ocidental.

Graças à herança do direito romano, a autonomia do fenômeno jurídico constituiu uma peculiaridade histórica do Ocidente, que pelo menos desde o Corpus Iuris Civilis tem se empenhado em mensurar adequadamente o peso e os efeitos deste seu legado. Com a redescoberta do Digesto pela especulação acadêmica medieval, há quase mil anos, a reflexão sobre o espólio romano contribuiu para moldar o pensamento jurídico europeu (e, por extensão, americano), sempre obrigado a revisitar o seu ilustre patriarca. Essa reflexão deu origem a uma sólida tradição de estudos sobre o direito romano, que apenas no século XX começou a dar sinais de crise.

Essa crise é o indício de um exaurimento de função. A sólida liga formada entre jusracionalismo e codificação no alvorecer da modernidade jurídica retirou à tradição romanística a "utilidade" que sempre teve, ainda que com conteúdo variável. A elaboração de uma ordem jurídica construída em torno das figuras da propriedade e do contrato, positivada em textos legislativos, enraizada com firmeza nos valores rígidos e universais de um direito natural antropocêntrico, e a extrair sua força coativa diretamente da soberania absoluta do Estado moderno, simplesmente tornou desnecessária a retomada do direito romano como elemento de legitimação, validação ou racionalização do direito vigente. O movimento codificador dá início a um processo de desgaste paulatino do direito romano como objeto de estudo, intimamente vinculado à perda de seu interesse prático como instrumento de compreensão ou aplicação do direito vigente.

Já no início do século XX se percebem sinais de crise da tradição romanística na Europa, que pouco a pouco exclui a disciplina da formação jurídica elementar. No Brasil ela se manifesta com vigor a partir de 1962, quando o Conselho Federal de Educação excluiu o direito romano do rol de disciplinas obrigatórias no currículo mínimo das Faculdades de Direito, agregando o seu conteúdo à cadeira de direito civil. As reformulações posteriores do ensino jurídico brasileiro (nos anos de 1970, 1980, 1990 e 2000) não modificaram o panorama: seja quando se privilegia a 
formação técnica profissional, destacada da formação romanística graças ao positivismo codificador; seja quando se enfatiza a formação humanista, alheia à dogmática romanística e mais atenta a um saber de caráter reflexivo; o fato é que os estudos de direito romano já não se mostram capazes, no início do século XXI, de renovar a milenar tradição².

O momento parece adequado, portanto, para uma revisão historiográfica dessa tradição. A saída de cena dos romanistas e civilistas abre o espaço para um novo olhar sobre o direito romano, tanto em sua versão "original” quanto nas releituras realizadas desde o Digesto. Como defende Aldo Schiavone (2005a, p. 18):

[La situazione] consente almeno di acquisire un punto di vista storiograficamente vantaggioso: quello di poter osservare finalmente dall'esterno e da lontano un'eredità che ci ha condizionato tanto $\mathrm{a}$ lungo, e che con tanta tenacia ha continuato a far parte del nostro orizzonte. Non sembra che finora gli studiosi di diritto romano abbiano saputo approfittare di questa nuova possibilità, presi come sono dalla nostalgia e dal rimpianto per le posizione perdute. Al contrario, noi cercheremo di farlo ${ }^{3}$.

Tratemos, então, de fazê-lo.

2 Na Universidade Federal do Paraná, a discussão voltou a ocorrer com vigor ao final de 2012: a aposentadoria da professora até então responsável por ministrar a matéria deu origem a um novo ciclo de discussões sobre a pertinência e a relevância da disciplina no currículo da graduação em Direito. Um grupo pequeno, mas organizado, de professores e estudantes defendia com vigor a sua extinção do currículo, sugerindo, com simbolismo estridente, a sua substituição por uma disciplina de Teoria dos Direitos Humanos - a tradição historicista cedendo lugar ao universalismo transcendental do neojusracionalismo. 3 "[A situação] permite ao menos adquirir um ponto de vista historiograficamente vantajoso: o de poder observar, finalmente do exterior e de longe, uma herança que nos condicionou por tanto tempo, e que com tanta tenacidade continuou a fazer parte do nosso horizonte. Não parece que até agora os estudiosos do direito romano tenham sabido se aproveitar dessa nova possibilidade, presos como são à nostalgia e ao lamento pelas posições perdidas. Pelo contrário, nós buscaremos fazê-lo". (SCHIAVONE, 2005, p. 18, tradução nossa) 


\section{A Romanística da Compilação: o Digesto e o passado como fundação (século VI)}

O trabalho de recuperação e atualização do direito romano não começou com o baixo medievo, mas com Justiniano. O tratamento descontextualizante da jurisprudência clássica pelo Digesto era já um primeiro nível daquele processo de desenraizamento do pensamento jurídico romano de seu ambiente e de sua história pela técnica jurídica, que conhecemos como tradição romanística.

O objetivo da compilação era preservar o saber jurídico dos séculos II-III, integrando organicamente os velhos iura (opiniões dos jurisconsultos e decisões dos magistrados) às novas leges imperiais. A necessidade de integração surge da proliferação legislativa que marca o período final do Principado: com o desaparecimento dos limites à autoridade do imperador, entre Diocleciano (284 d.C.) e Constantino (337 d.C.), a administração do Império assume a estrutura de uma burocracia, que exerce o monopólio do direito através de leis gerais. Os imperadores passam a desenvolver a sua atividade normativa, sobretudo através de éditos, que abordam os problemas da administração pública, organização econômica e justiça penal, mas também a legislação de direito privado. $\mathrm{O}$ caráter fragmentário e desordenado das leis imperiais, a variação da sua eficácia, a divisão administrativa do império em partes distintas, e mesmo a dispersão das opiniões dos juristas clássicos em um sem número de livros, conduzem à defesa de uma "codificação" do direito vigente, de modo a facilitar sua consulta e manuseio.

Como explica Bretone (1998, p. 272), o “código" é, acima de tudo, a forma livreira, que substitui o rolo de papiro entre os séculos I e IV d.C. por sua funcionalidade, resistência e economicidade. Porém, mais que razões econômicas, o códice é sinal de uma transformação psicológica, a expressão simbólica de uma cultura da palavra transformada em discurso escrito, e de uma compreensão autoritária do texto como manifestação do poder imperial ${ }^{4}$.

4 O papiro é referência para a recordação e a recitação: sua utilização exige que seja desenrolado lentamente, enquanto se realiza a sua leitura em voz alta, para a fixação de 
Após algumas tentativas de codificação não oficial (Códice Gregoriano, 291-292 d.C.; Códice Hermogeniano, 293-294 d.C.) e oficial do direito (Código Teodosiano, 438), mesmo por parte dos reis bárbaros (Edito de Teodorico, séc. V; Códice de Eurico, 470; Breviário de Alarico, 506; Lex Romana Burgundionum, século VI), uma burocracia erudita recolhe à sua maneira, no Império do Oriente, a herança da jurisprudência romana - em um conjunto de textos que acabou ficando conhecido como Corpus Iuris Civilis.

No momento da redação do Corpus Iuris Civilis, os estudos jurídicos estavam passando por um momento de retomada e desenvolvimento. Nos séculos V e VI se desenvolve em Constantinopla uma série de pesquisas fundadas na recuperação dos antigos mestres, marcadas pela sua inquestionável autoridade e por um sentimento de veneração pelo passado perdido. A iniciativa se ligava também a uma visão política estratégica, de tonalidade universalista, que pretendia a reconquista militar da Itália, a reunificação do Mediterrâneo e a restauração do Império (propósitos efetivamente realizados, embora de modo efêmero, entre 533 e 554 d.C.).

Justianiano havia começado por ordenar, em 528, uma coletânea de constituições imperiais desde a era de Adriano até os seus próprios dias. Com isso se construiria um amplo Codex, que deveria substituir as três obras precedentes - o Códice Gregoriano, o Códice Hermogeniano e o Códice Teodosiano -, organizando o acúmulo de legislações plurisseculares. Dois anos mais tarde confiou ao ministro Triboniano o encargo de elaborar uma coletânea de textos extraídos dos escritos mais importantes dos antigos juristas (desde Quinto Múcio Scevola, início do I a.C., até Hermogeniano e Arcadio Carisio, final do século III d.C.). Seria o Digesto, que pretendia remodelar o pensamento dos antigos mestres na forma de um direito codificado. O panorama é completado pelas Novellae, compostas pelo conjunto de novas constituições imperiais promulgadas após o Codex, e pelas Institutiones, que contêm os primeiros elementos do direito, voltadas ao ensino jurídico.

seus conteúdos na memória. O livro é, acima de tudo, arquivo de autoridade: a facilidade de consulta imediata a cada uma das suas páginas não exige a sua leitura integral, e reflete uma cultura que já não depende da memória para se desenvolver, pois o discurso proferido em público foi substituído pela palavra escrita. 
A retomada do direito romano clássico pelo Digesto tem uma clara função política: na estrutura do código se exprime a vocação absolutista e centralista do aparato de governo imperial. É o que se percebe no texto da Constituição Deo Auctore, que ordenou a sua elaboração: a coletânea de obras dos juristas antigos é, por um lado, "restituída à sua pureza" pela atividade científica liderada pelo imperador; por outro lado, é "defendida como um baluarte" pelo próprio imperador, que se apresenta como defensor da tradição e do espírito romanos. Com isso, o imperador encontra um forte fundamento de legitimidade para o exercício do seu poder (a tradição jurídica romana, a justiça, a benevolência divina), ao mesmo tempo em que promove uma ressignificação dos próprios textos da tradição, "restituídos à sua pureza" pela própria atividade imperial.

Ordenamo-vos, portanto, que examineis e emendeis as obras que, sobre o direito romano, escreveram os juristas antigos, a quem os sagrados imperadores concederam a faculdade de redigir e de interpretar as regras jurídicas, para que se recolha daquelas obras todo o material necessário; não se deixe, nos limites do possível, nenhuma repetição ou discordância, mas consiga-se com esse livro que, único, as substitua a todas. Também outros, para dizer a verdade, escreveram obras jurídicas, que não foram citadas ou utilizadas por nenhum autor; nós não achamos conveniente que elas alterem o nosso projeto legislativo. Quando este material, com a ajuda da benevolência divina, tiver sido recolhido, será preciso reorganizá-lo magnificamente, quase erguendo à justiça um duradouro, venerável templo. Todo o direito deverá ser distribuído em cinquenta livros e em títulos determinados, tomando como modelo, quer o nosso Código, quer o Edito Perpétuo, conforme vos pareça mais conveniente; deste modo, nada se deixará de fora da coletânea, mas nos cinquenta livros todo o direito antigo que se acumulou desordenadamente ao longo de mil e quatrocentos anos, e por nós restituído em sua pureza, será defendido como um baluarte, e não terá nada fora de si. Todos os juristas chamados têm uma igual dignidade, e a nenhum deles deve ser reconhecido qualquer privilégio: porque ninguém é sempre superior ou inferior aos outros, mas cada um o é, a cada vez, em determinados aspectos (JUSTINIANO, 530: Constitutio Deo Auctore) 
A compilação dos textos jurisprudenciais em um livro oficial os transforma em autêntico texto normativo, combinando-se a autoridade da tradição com a autoridade política do imperador. $\mathrm{O}$ glorioso passado romano aparece como elemento de refundação da nova ordem mundial: o venerável saber dos antigos juristas retorna à luz, sob a curadoria do legislador contemporâneo, como instrumento privilegiado da providência divina, responsável por completar o desenho de perfeição de uma experiência jurídico-militar livre de imperfeições ou lacunas, garantindo previsibilidade à sociedade e à máquina burocrática bizantina. Apenas seis meses antes de ser completado o Digesto (dezembro de 533), uma imponente frota de navios de guerra havia partido para a reconquista do $\mathrm{Me}-$ diterrâneo. Renova-se, com a sua edição, a conexão entre armas e direito que havia assegurado a fortuna da Roma imperial.

$\mathrm{O}$ antigo se apresenta como patrocinador da autoridade, conferindo prestígio aos novos conteúdos jurídicos, que aparecem nos interstícios do mosaico jurisprudencial. Mas a principal fonte do direito continua sendo a lei imperial, e o retorno ao passado se verifica no estilo, mas não nos conteúdos normativos - continuando a se desenvolver a tendência simplificadora e unificadora do direito privado, aprofundando-se o fiscalismo e o corporativismo da política legislativa imperial. A recuperação do direito do passado e a sua organização sob o modelo de antologia não servem tanto para que retome a sua vigência, mas acima de tudo para a sua conservação.

Como explica Schiavone (2005a, p. 12), a "forma-código" era um recipiente resistente para a preservação do direito romano, mas também um espelho gravemente deformante, que alterava os termos autênticos daquela cultura ao mesmo tempo em que contribuía para salvar a sua recordação. Em seu interior, o desenvolvimento real do raciocínio jurídico era destruído e preservado. Nada surpreendente; afinal, não se buscava o conhecimento do pensamento jurídico clássico ou de seu contexto de formação, mas a recuperação de um passado venerável que pudesse contribuir para refundar a glória do antigo império. Uma retomada ressignificadora e homogeneizante do passado no presente, bem a gosto da tradicionalista visão romana da política. 
Um exemplo importante dessa fundação político-jurídica do presente a partir da recuperação da tradição da jurisprudência romana se percebe no estudo realizado por Aldo Schiavone (2005a, p. 285) acerca da definição de Direito como "arte do bom e do équo", no Digesto:

É preciso que aquele que há de se dedicar ao direito primeiramente saiba de onde descende o nome "direito" (ius). Vem, pois de "justiça" (iustitia) chamado. De fato, como Celso elegantemente define, direito é a arte do bom e do équo (ULPIANO, Digesto, 1.1.1pr.)

Com base neste direito Celso nos denomina sacerdotes: pois cultuamos a justiça e professamos o conhecimento do bom e do équo, separando o équo do iníquo, distinguindo o lícito do ilícito, desejando que os homens bons se façam não só pelo medo das penas mas também pela motivação dos prêmios, aspirando não à simulada filosofia, se não me engano, mas a verdadeira. (ULPIANO, Digesto, 1.1.1.1)

A definição citada é construída originalmente por Celso em II d.C., período de cristalização do pensamento jurídico romano graças à sistematização do ius civile e do ius honorarium pela tradição jurisprudencial, em aliança com o príncipe. Nesse contexto, a recuperação do bonum et aequum da antiga tradição pretoriana (século II a.C.) funciona como convite ao redescobrimento de uma atitude: aquela de buscar regras flexíveis, medidas sobre o caso concreto, mutáveis no curso do tempo, adaptadas a restabelecer os equilíbrios rompidos pelas circunstâncias: uma capacidade romana formatada longe de qualquer concepção jusnaturalista. No entanto, ao ser citada por Ulpiano em III d.C., já tem outra função discursiva: transmitir a mensagem de que não pode existir direito (ius) sem justiça (iustitia). A ligação impedia que o ius se justificasse somente no interior do isolamento formal de seus próprios procedimentos constitutivos (jurisprudenciais ou legislativos), exigindo uma valorização ética externa ao próprio poder do príncipe. Por fim, ao ser retomada no Digesto (VI d.C.) a frase se afirma como teoria de fundo teológico e transcendental: a referência à iustitia e ao aequum confere uma moldura mística e transcendental ao saber jurídico, compatível com a sensibilidade do tempo e 
com a justificação teológica do poder imperial, atribuindo à legislação do imperador um fundamento transcendental de legitimidade.

\section{A Romanística da Exegese: a interpretatio e o passado como validade (século XI)}

Embora o conhecimento do Codex, das Institutiones e das Novellae se tenha conservado sempre com alguma continuidade, justamente o $\mathrm{Di}$ gesto, que representava a parte mais importante da Compilação, se perdeu durante todo o Alto Medievo (ainda que não se possa falar de um efetivo desaparecimento). À sua falência como código para a sociedade bizantina correspondeu o obscurecimento de seu conhecimento no Ocidente.

Os responsáveis pela redescoberta do saber jurídico-científico romano foram os mestres bolonheses que, em torno do final do século XI, começaram a trabalhar sobre uma cópia do Corpus Iuris Civilis, a Littera Bononiensis, reconstituída a partir da Littera Florentina. O seu exemplo constitui a primeira agregação que conduziria ao nascimento da Universidade: nessa nova instituição, o estudo do direito romano obtém rapidamente um reconhecimento quase igual ao da teologia, e uma autonomia que o tornava imune a um condicionamento religioso muito estreito. A tradição romanística é então retomada, mas com um novo objetivo, distinto daquele de refundação política almejado pela compilação do Digesto.

Na sociedade protomedieval, estática e dominada por um forte naturalismo, o problema da validade do direito não é percebido com força, sendo superado sem dificuldades pela ideia central de fato normativo, e pela concepção de um direito reicêntrico que extrai a sua validade diretamente dos usos e costumes. Mas a sociedade que se desenvolve a partir dos séculos XI e XII, mais dinâmica e complexa, passa a enfrentar problemas pela ausência de um direito que, sem trair os fatos, fosse capaz de ordená-los em esquemas abstratos, passíveis de aplicação às novas necessidades sociais.

Diante da incapacidade do costume de prover uma ordenação jurídica desse tipo, confia-se à ciência a tarefa de organizar racionalmente os 
conceitos e institutos abstratos extraídos da realidade factual. Porém, destacada do poder cogente dos costumes tradicionais, e incapaz de contar com a força coativa do poder político (fragmentado, plural e incapaz de criar direito, segundo a concepção medieval de iurisdictio), a scientia iuris se vê obrigada a encontrar algum fundamento de validade para as suas construções teóricas, de modo a garantir a imperatividade de um saber jurídico produzido de forma especulativa.

É nesse contexto que se compreende a importância da recuperação do direito romano justinianeu: por um lado, fornece a sofisticação técnica buscada pelo saber jurídico na ordenação das complexidades da nova realidade social; por outro lado, pode atuar como fundamento de validade da nova ordem jurídica construída pelos doutores do direito. Afinal, trata-se de um complexo normativo revestido de sacralidade, que extrai sua autoridade não somente do poder político e da legitimidade axiológica de um imperador católico, mas também de sua venerável antiguidade, que o reveste da indiscutível respeitabilidade que o decorrer dos séculos confere, conforme a opinião do erudito medieval. Recebido por uma longa cadeia de gerações, o Digesto se apresenta como auctoritas, desvinculado de juristas ou governantes particulares, voz de uma grande comunidade tradicional, e por isso garantia de fundação sólida para o novo direito.

A partir desse momento, o direito se apresenta como comentário. Com uma atitude filosófica realista, glosadores e comentadores desenvolvem a sua investigação a partir do texto romano, extraindo dele o fundamento de validade necessário à nova ordenação social. Não se trata de mera descrição analítica dos textos originais; busca-se compreender a natureza das instituições jurídicas, a partir de métodos racionais que permitam a construção de conceitos abstratos inovadores. No entanto, a ideia de que o direito consiste em um conjunto de normas cuja ordem o intérprete não pode alterar faz com que essa atividade produtora de conceitos jurídicos tenha de ser travestida como interpretação.

De fato, o Corpus Iuris Civilis reflete uma organização social e econômica bastante diversa daquela do tardo-medievo. No entanto, é ele a única fonte de validade a garantir a vigência prática da construção teórica dos glosadores e comentadores, sem a qual ela se tornaria mera especu- 
lação metafísica. Desse modo, os juristas medievais não podem simplesmente descartar o direito romano e reiniciar do zero, pois dependem dele como elemento de juridicidade do saber produzido. A trajetória teórica dos glosadores e comentadores se desenvolve sempre entre a necessidade de certeza e estabilidade da norma romana válida e a exigência de se construir um direito efetivo, ligado aos fatos e coerente com a nova realidade social.

O equilíbrio se encontra com a noção de interpretatio. Toda a realidade jurídica medieval é concebida como atividade interpretativa, caracterizando-se como interpretatio a atividade normativa do príncipe, a da comunidade pelo costume, a aplicação da justiça pelo juiz e a edificação teórica do magister. Uma concepção de direito como realidade objetiva, a ser extraída da natureza por uma atividade racional, não poderia se desenvolver de outra forma: se o direito não pode ser criado (exceto pelo Criador divino), resta aos homens uma observação atenta da realidade, para extrair, da própria ordem natural, os princípios de ordenação jurídica da sociedade.

Compreende-se que a interpretatio medieval não se confunde com a hermenêutica positivista moderna: afinal, não se trata de atividade puramente lógica de subsunção do fato à norma, mas de extração racional da ordem normativa a partir de uma observação atenta da realidade. Como ressalta Grossi (2011, p. 164), não se caracteriza como processo meramente cognoscitivo da norma, mas também como ato de vontade e liberdade do intérprete, que age corrigindo, estendendo, restringindo ou modificando a abrangência da norma. Era a própria Magna Glosa a defini-la desta forma: "Interpretor, idest corrigo [...] Item verbum apertius exprimo [...] item arrogo, item prorogo, sed econtra corrigo id est addo ${ }^{5}$.

Com isso, preserva-se o fundamento de validade do direito (o venerável texto romano), ao mesmo tempo em que se permite o desenvolvimento de novas soluções jurídicas para os novos problemas da dinâmica sociedade do baixo medievo. O ponto de partida é o dado normativo, ou

5 "Interpreto, isto é, corrijo. Igualmente, exprimo mais claramente o significado de uma palavra; igualmente, acrescento, igualmente, estendo; ao contrário, corrijo, isto é, adiciono". (tradução nossa) 
seja, a lex romana: no entanto, o que se busca com a interpretatio é a ratio legis, e não os meros verba que uma interpretação gramatical pudesse extrair do texto normativo. A ratio é identificada com a aequitas, e tomada como base de um procedimento analógico que busca, no caso concreto, não a solução técnica abstrata preconizada pelo texto original, mas a aplicação da mesma justiça material por ele almejada. Esse raciocínio de interpretação por equidade permite uma grande liberdade de ação ao juiz e ao doutor, e permite a construção, pelo saber jurídico, de novas soluções jurídicas para os novos problemas enfrentados por essa sociedade em transformação.

Como se percebe, é novo o papel desempenhado pela romanística medieval: colocado em termos modernos, não se trata mais de um problema de legitimidade, mas de um problema de validade do direito. Em vez de se retomar o direito do passado como momento de fundação do novo poder imperial, por sua passagem pelo filtro da autoridade política do príncipe, tem-se uma situação inversa de incompletude do poder político, gravada pela necessidade de atribuição de um elemento de força à nova scientia iuris. O passado é novamente retomado; não como momento de refundação do poder político, mas como elemento de validação de um direito novo produzido pela interpretatio da tradição.

Percebe-se a retomada do direito romano como critério de validade para um direito medieval inovador na doutrina medieval do domínio diviso, explicada por Paolo Grossi. Segundo Grossi (2011, p. 210), o direito romano resolvia o mundo dos direitos reais no esquema do pertencimento: um esquema unitário, fundado na ideia de dominium absoluto e exclusivo sobre a coisa. Os juristas medievais realizam um trabalho de sistematização das situações reais nos termos do dominium, as repensando a figura para afirmar a existência de dominia, no plural - com a teoria do domínio diviso.

Desse modo, no direito medieval não se reconhece um domínio exclusivo sobre a coisa, mas uma divisão entre domínio direto e domínio útil: sobre uma mesma coisa são possíveis duas situações de pertencimento, uma relativa ao núcleo interno da coisa (substantia rei) e outra relativa a seu aspecto externo e economicamente fruível, a utilidade (utilitas 
rei). Assim são estabelecidas duas relações de propriedade sobre o mesmo bem, de modo a se proteger situações de efetividade jurídica verificadas na realidade econômica. Mas permanece o problema de como dar fundamento de validade (romano) a esta doutrina, especialmente diante do dogma romano da unicidade do dominium.

O fundamento é encontrado no próprio Digesto, em um texto de Paulo (D. 6.3.1) que se refere às agri vectigales - fundos de entes públicos que, por motivos de política agrária, eram locados em condições mais vantajosas que as locações comuns entre os privados.

Agri civitatium alii vectigales vocantur, alii non. Vectigales vocantur qui in perpetuum locantur, id est hac lege, ut tamdiu pro his vectigal pendatur, quamdiu neque ipsis, qui conduxerint, neque his, qui in locum eorum successerunt, auferri eos liceat: non vectigales sunt, qui ita colendi dantur, ut privatim agros nostros colendos dare solemus.

1. Qui in perpetuum fundum fruendum conduxerunt a municipibus, quamvis non efficiantur domini, tamen placuit competere eis in rem actionem adversus quemvis possessorem, sed et adversus ipsos municipes, Ita tamen si vectigal solvant (PAULO, Digesto, 6.3.1)

Àqueles que fruem de um fundo perpétuo, ainda que não sejam os proprietários, também lhes foi concedida uma ação real contra quem viole a sua posse (PAULO, Digesto, 6.3.1)

Entre essas condições mais vantajosas estava a concessão de uma ação real para a tutela dos interesses do locador. A singularidade de tratamento é precisada por Paulo em seu texto: "mesmo que não sejam criados domini, lhes foi concedida uma ação real". Em outras palavras: os locatários têm uma tutela qualificada, real, mas que não tem qualquer relação com a propriedade do fundo.

Em suma, o texto de Paulo reitera o dogma da unicidade do domínio, reconhecendo, porém, que mesmo sem domínio se atribuiu aos locatários o direito a uma ação real - conclusão oposta à pretendida pelos juristas medievais. No entanto, é justamente sobre este texto que os glosadores irão trabalhar, fazendo-o dizer algo que Paulo não quis e nem 
pensou. Como explica Grossi, Paulo escreve "tamquan non efficiantur domini, placuit eis concedere actionem in rem"; nesta frase, domini é apelativo geral sem a sombra de uma limitação. O glosador escreve, porém, limitando a palavra domini como "scilicet directo", isto é, "proprietários diretos". O advérbio permite a extrapolação completa do conteúdo original do texto de Paulo.

Para Paulo, a propriedade (que é uma só) permanece nas mãos do concedente. Para o glosador, permanece nas mãos do concedente o novo "domínio direto", mas se assegura ao vetigalista o outro domínio, o "domínio útil". Ao reconhecer-se a existência de uma rei vindicatio utilis ao lado da rei vindicatio, extrai-se do direito processual o direito material, tornando-se possível concluir que a rei vindicatio utilis é a manifestação processual de uma situação substancial correspondente, o domínio útil.

Com isso se assegura a validade jurídica de uma série de situações de efetividade sobre o bem (enfiteutas, feudatários, superficiários, locadores por longo tempo), que cumpriam um papel importante no tecido econômico da sociedade. Percebe-se como o ponto de partida no direito romano, que fornece o desenho formal do instituto, aliado ao trabalho criativo da interpretatio dos juristas, preocupados com as diversas situações de efetividade econômica sobre o bem, torna possível uma completa subversão do texto romano para que lhe sejam atribuídos novos sentidos, mais compatíveis com a realidade social do medievo. O texto continua a fundar formalmente o discurso no plano da validade, mas é completamente esvaziado de seu conteúdo original.

\section{A Romanística da Razão: o instituto jurídico e o passado como essência (século XIX)}

A tradição romanística do Ocidente também recebeu uma forma especificamente moderna. A retomada do direito romano está relacionada à crise do jusracionalismo iluminista, que, após afirmar a existência de um direito natural de caráter universal e eterno, vê-se obrigado a lidar com a contínua transformação do direito e a sua adaptação às novas necessidades históricas. A crítica se desenvolve com mais vigor especialmente 
naquelas nações em que o Estado Nacional não havia se formado, como nos estados alemães da Europa central: nesse contexto, a ausência de uma legislação codificada permitiu a reação contra uma concepção fixa e imobilista do direito vigente, que se materializou no projeto teórico da Escola Histórica do Direito.

A recusa dessa função criadora ao Estado conduz a uma valorização das formas tradicionais e espontâneas de organização política e jurídica, a serem encontradas especialmente na tradição nacional. Constrói-se, assim, uma concepção de ciência do direito que extrai a sua essência não mais de uma razão universal abstrata, mas da própria história, retomando-se a tradição romanística como matriz de esquemas e conceitos diretamente aplicáveis à realidade jurídica do presente.

O programa da Escola Histórica era o de buscar as fontes não estatais e não legislativas do direito. Compreende a sociedade como um todo orgânico, sujeito a uma evolução histórica semelhante à dos seres vivos, em que no presente se lêem os traços do passado, e em que este condiciona naturalmente o que vem depois. Em toda essa evolução se manifesta uma lógica própria, o espírito do povo, que estaria na origem e daria unidade e sentido a todas as manifestações histórico-culturais de uma nação - inclusive o direito.

Esse modo de se compreender o direito gera uma concepção de ciência jurídica simultaneamente histórica e filosófica. A "história" representa a fase empírica da ciência do direito, em que o jurista observa na realidade o desenvolvimento histórico de um determinado instituto jurídico para extrair os dados necessários ao seu conhecimento científico; a "filosofia" representa a fase abstrata do procedimento, em que o jurista promove uma ordenação racional dos dados empíricos coletados para uma sistematização orgânica desse todo unitário. Como explica Wieacker (2004, p. 421), a pesquisa histórica serviria para averiguar a matéria jurídica, estabelecida pela tradição dos textos normativos e da ciência do direito; a elaboração filosófica, por sua vez, deveria organizar essa matéria em um sistema formal, que não fosse um mero agregado de normas jurídicas, mas manifestasse a coerência espiritual de toda a matéria jurídica - 
conforme a proposta epistemológica de Immanuel Kant (1999, p. 494) em sua Crítica da Razão Pura.

Com isso, a retomada da tradição romanística se dá em função da sua utilidade concreta para a constituição do sistema jurídico. Na medida em que o espírito do povo é uma realidade cultural, e que o direito romano se tornara, ao menos desde o usus modernus pandectarum, um elemento essencial da vida jurídica alemã, também deve ser estudado como elemento de compreensão da história do direito alemão. Contudo o que se busca, nessa perspectiva, não é propriamente o direito romano, em si, mas uma ligação direta capaz de extrair do pensamento jurídico romano a essência dos institutos vigentes no direito do presente - subtraindo-se o direito romano ao seu contexto particular e inserindo-se-o na trajetória espiritual da civilização humana.

Desse modo, toma-se o direito romano como objeto de uma atenção que pretende extrair, não o texto normativo do passado, mas a longa história evolutiva dos institutos jurídicos vigentes no presente. O sentido da pesquisa histórica está, portanto, em encontrar esse "laço vivo" entre presente e passado, que permite "penetrar no espírito" do direito vigente e encontrar nele, a partir do estudo do direito romano, a sua essência. É esta a posição de Savigny (1878, p. 4):

Pretender, como se ha hecho à menudo, que la ciencia mirada bajo el punto de vista histórico estabelece la forma antigua del derecho como tipo absoluto e inmutable para el presente y para el porvenir, es desfigurar completamente este punto de vista, cuyo verdadero sentido nos enseña, por el contrario, a reconocer el mérito y la independencia de cada siglo y trata, sobre todo, de aclarar el lazo vivo que liga el presente con el pasado, bajo el concepto de que, si esta relacion se nos oculta, podriamos ver las manifestaciones exteriores del derecho, pero no penetrar su espíritu. Esta doctrina, en su aplicación particular al derecho romano, no le reconoce, como à menudo se piensa, una autoridad sin límites, sino que estudia el conjunto del derecho moderno, a fin de descubrir y de fijar todo lo que tiene un orígen romano cierto, para evitar que, inconscientemente, seamos por él dominados; despues, descompone el elemento romano, y si alguna de sus partes, muertas en realidad, no conservan mas que la apariencia 
de la vida, la elimina, abriendo así un campo más libre al desarrollo y a la accion saludable del elemento existente ${ }^{6}$.

Como explica Larenz (1983, p. 12), se a fonte do direito está no espirito do povo, ele não pode ser construído por dedução lógica, mas somente por uma intuição imediata. Essa intuição se extrai de formas de conduta concretas e típicas, que, justamente pela consciência de sua necessidade intrínseca, são espontaneamente observadas pelo conjunto dos cidadãos. Tais formas de conduta, na medida em que se organizam como ordem juridicamente vinculante, constituem os institutos jurídicos, origem e fundamento de toda a evolução do direito.

Apesar de utilizado como mero veículo de tradição do instituto jurídico, o direito romano tem uma importância especial. Se a preocupação da Escola Histórica do Direito fosse somente histórica, o mesmo grau de importância seria atribuído à história do direito germânico, que, apesar de realizada, tem um papel precário e pouco nítido entre os juristas do século XIX. A verdade é que o direito romano, em sua fase clássica, representa para esses juristas também um modelo perfeito e acabado da racionalidade sistematizadora de institutos jurídicos materiais - sendo considerado, portanto, também como modelo para a construção da moderna ciência do Direito.

6 "Pretender, como se fez frequentemente, que a ciência observada do ponto de vista histórico estabelece a forma antiga do direito como tipo absoluto e imutável para o presente e para o devir, é desfigurar completamente este ponto de vista, cujo verdadeiro sentido nos ensina, pelo contrário, a reconhecer o mérito e a independência de cada século e trata, sobretudo, de esclarecer o laço vivo que liga o presente com o passado, sob o conceito de que, se esta relação nos é oculta, poderíamos ver as manifestações exteriores do direito, mas não penetrar em seu espírito. Esta doutrina, em sua aplicação particular ao direito romano, não lhe reconhece, como amiúde se pensa, uma autoridade sem limites, mas estuda o conjunto do direito moderno, a fim de descobrir e de fixar tudo o que tem uma origem romana certa, para evitar que, inconscientemente, sejamos dominados por ele; após, decompõe o elemento romano, e se alguma das suas partes, mortas na realidade, não conservam mais que a aparência da vida, a elimina, abrindo assim um campo mais livre ao desenvolvimento e à ação saudável do elemento existente". (SAVIGNY, 1878, p. 4, tradução nossa) 
Com isso, o direito romano é apresentado como ponto de referência insuperável para a solução racional de conflitos. A sua "elaboração filosófica" é tomada como padrão de racionalidade jurídica, e objetivo ainda por ser alcançado pela moderna ciência do direito (até como pré-condição para uma codificação nos moldes da realizada pelo Corpus Iuris Civilis). Além disso, é também o motor de uma tradição que atravessa intacta a era medieval e moderna, da qual o presente é herdeiro, e de que pode se apropriar para resolver os problemas atuais.

Como se vê, a compreensão do passado não encontra a sua legitimidade em si mesma; é o presente o critério de valoração do passado, o parâmetro a partir do qual se julga a relevância ou a irrelevância do direito romano. Nas palavras de Pietro Costa (2010, p. 69), “[...] o neopandectista não interpreta, mas usa os textos do passado [...]", para construir esquemas, modelos e argumentos funcionais às necessidades cognoscitivas e práticas do presente. Uma estratégia bastante distinta, portanto, daquela adotada pela romanística antiga e medieval: o que interessa à romanística moderna não é a legitimidade fundadora do direito romano; tampouco a sua autoridade, a permitir interpretações inovadoras dotadas de validade jurídica; mas os seus conteúdos, como essência original dos institutos jurídicos do presente, e a sua lógica, padrão de sistematicidade a ser adotado pela ciência jurídica atual. Esclarece Franz Wieacker (2004, p. 479):

A Escola Histórica distingue-se antes da tradição da jurisprudência elegante precisamente pela tentativa, pensada a-historicamente, de utilizar a sistemática e o aparato coneitual da jurisprudência contemporânea por si renovada também para a exposição da dogmática antigo-romana. Ela não podia, no entanto, transformar-se numa ciência puramente histórica enquanto o direito romano permanecesse ao serviço da dogmática do direito vigente. Uma compreensão histórica livre teria destruído uma interpretação do texto das Pandectas que pudesse servir à atualidade; uma crítica textual ilimitada teria ameaçado os resultados seguros de uma harmonização engenhosa das Pandectas.

Pode-se observar este trabalho de retomada do passado jurídico romano para a compreensão da essência de um instituto jurídico moderno 
na teoria subjetiva da posse de Savigny (1870), tal como exposta em seu Tratado da Posse no Direito Romano. Savigny (1870) observa que no direito romano apenas se atribuem à posse dois efeitos legais independentes da propriedade: a usucapião e os interditos possessórios. Desse modo, parte da constatação de que o direito romano concede tutela processual aos possuidores para deduzir a existência da possessio como direito material. Concluindo pela existência da possessio, define os seus elementos constituintes com base na jurisprudência romana, partindo da citação de Celso no Digesto (41.2.18):

Quod meo nomine possideo, possum alieno nomine possidere: nec enim muto mihi causam possessionis, sed desino possidere et alium possessorem ministerio meo facio. Nec idem est possidere et alieno nomine possidere. Nam possidet cujus nomine possidetur. Procurator alienae possessioni praestat ministerium. (CELSO, Digesto, 41.2.18)

O trecho de Celso demonstra que não é preciso ser proprietário para ter a posse, bastando que pretenda dispor da coisa como se fosse proprietário. Desse modo se conclui que é possível possuir em nome alheio, e que se pode ter uma posse derivada mesmo sem a detenção da coisa.

Nous avons dit plus haut que la détention d'une chose est un fait physique correspondant au fait juridique de la proprieté. En consequénce l'animus possidendi n'est autre chose que l'intention d'exercer le droit de proprieté. Cette définition cependant ne suffit pas, car celui qui détient une chose peut avoir cette intention de deux manières différentes : il peu vouloir exercer le droit de proprieté d'autrui ou le sien propre. S'il a l'intention d'exercer le droit de proprieté d'autrui, droit qu'il reconnaît par là même, il n'y a pas là cet animus possidendi qui est nécessaire pour que le fait de la détention se transforme en possession. Cette proposition, que le droit romain établit en termes formels, s'explique très naturellement par ce que nous avons dit, pages 7 et 8, sur les interdits. Il ne reste, donc, que la seconde hypothèse, celle où le détenteur a l'intention d'exercer son propre droit de proprieté, en sorte que l'animus possidendi n'est ici autre chose que l'animus domini ou l'animus 
sibi habendi. Ainsi, pour être consideré comme véritable possesseur d'une chose, il faut nécessairement que celui qui la détient se gère à son égard en propriátaire ; en d'autres termes, qu'il prétende en disposer en fait comme un propriétaire aurait la faculté légale de le faire en vertu de son droit, ce qui implique en particulier aussi le refus de reconnaître dans le chef d'autrui un droit quelconque supérieur au sien. L'idée de la possession n'exige absolument rien de plus que cet animus domini ; et surtout elle ne suppose pas la conviction que l'on soit réellement propriétaire (opinio seu cogitatio domini) ; voilà pourquoi le voleur et le brigand peuvent tout aussi bien avoir la possession de la chose volée que le propriétaire lui-même, et ils différent de la même manière que celui-ci du fermer qui, lui, ne possède pas, puisqu'il ne considère pas la chose comme sienne ${ }^{7}$. (SAVIGNY, 1878, p. 88-91)

O que se extrai do direito romano não é a norma jurídica do passado, nem a forma vazia, mas apta a conferir validade, da regra; Savigny busca no passado aquilo que considera como a essência do direito de

7 Foi dito anteriormente que a detenção de uma coisa é um fato físico correspondente ao fato jurídico da propriedade. Em consequência o animus possidendi não é nada além da intenção de exercer o direito de propriedade. Mas essa definição, agora, já não é suficiente, pois aquele que detém uma coisa pode ter essa intenção de duas maneiras diferentes: ele pode querer exercer o direito de propriedade de outrem, ou o seu próprio. Se ele tem a intenção de exercer o direito de propriedade de outrem, direito que reconhece por si só, ele não tem este animus possidendi que é necessário para que o fato da detenção se transforme em posse. Essa proposição, que o direito romano estabelece em termos formais (D. 41.2.18) se explica muito naturalmente pelo que dissemos, às páginas 7 e 8 , sobre os interditos. Só nos resta, então, a segunda hipótese, em que o detentor tem a intenção de exercer o seu próprio direito de propriedade, de modo que o animus possidendi não é outra coisa que o animus domini ou o animus sibi habendi. Assim, para ser considerado como verdadeiro possuidor de uma coisa, é preciso necessariamente que aquele que a detém se se afirme como seu proprietário; em outros termos, que ele pretenda dispor, de fato, do modo como um proprietário teria a faculdade legal de fazer em virtude de seu direito, o que implica, em particular, também a recusa de reconhecer qualquer direito superior ao seu. A ideia da posse não exige absolutamente nada além deste animus domini; e sobretudo, ela não supõe a convicção de que o sujeito seja realmente proprietário (opinio seu cogitatio domini); eis porque o ladrão e o salteador podem ter a posse da coisa roubada tanto quanto o proprietário, e ambos diferem daquele que não possui, por não considerar a coisa como sua. (SAVIGNY, 1878, p. 88-91, tradução nossa) 
posse, que caracteriza como sendo o animus possidendi, necessário para que o fato da detenção se transforme em posse. Assim, encontra no direito romano a essência do instituto jurídico moderno, de fato, utilizando-o não para a validação ou a justificação, mas para a construção racional de um conceito de posse atual.

Da mesma forma que a recuperação dogmática da jurisprudência romana impediu o aprofundamento de sua compreensão histórica, que, se realizada com rigor, poderia destruir a harmoniosa sistematicidade construída por um delicado trabalho de ressignificação e reconstrução técnica, a crise da dogmática romanística viria a permitir a sua retomada pela perspectiva da história do direito. Somente com a codificação do direito privado, e o definitivo abandono das fontes romanas pela civilística fundada no jusracionalismo, é que a história do direito teria o seu caminho novamente liberado, para abordar o direito romano com seu próprio instrumental teórico-metodológico.

\section{A Crise da Tradição Romanística: a história e o passado como labirinto (século XX)}

O Digesto foi criado para desafiar o tempo: com ele, o direito romano se destaca completamente do mundo que o havia produzido, para iniciar uma nova e longa vida, em que a reproposta do passado se apresentaria como instrumento para o nascimento de novas formas e significados jurídicos. O seu processo de descontextualização começa já no projeto de Justiniano, que tornou possíveis todas as releituras posteriores, das épocas medieval e moderna. Tomado completamente por exigências atualizantes, o olhar dos romanistas se dissociou completamente da história antiga, dando origem a uma tradição peculiar, própria do mundo jurídico, e fundamental para a constituição da scientia iuris ocidental.

É somente no século XX, com o sucesso do movimento codificador e o desenvolvimento do positivismo jurídico, que surgem novas perspectivas para o estudo do direito romano. É justamente a crise da tradição romanística a pavimentar essa estrada, a partir do momento em que a inu- 
tilidade prática do direito romano torna possível a sua recontextualização histórica, e desnecessária a sua utilização dogmática pela civilística.

Mas, como defende Schiavone (2005a, p. 24), para isso é necessário alterar completamente a perspectiva: projetar, ao contrário, a sequência de composição do Digesto, esquecer o código, desmontar o mosaico pedaço a pedaço e reconstruir a antologia, não segundo o implante sistemático que lhe havia sido imposto, mas recolhendo os trechos singulares autor por autor e obra a obra, reapresentando o contexto original de cada escrito, até recompor, nos limites do possível, o perfil intelectual de cada jurista recordado na compilação. $\mathrm{O}$ estudo crítico do direito romano conta, entre seus deveres, o de quebrar a aparente evidência da linguagem, recuperando o seu estranhamento mesmo diante da aparência de identidade e continuidade.

É claro que isso não significa a morte da dogmática como instrumento de abordagem do direito romano. No entanto, ela não serve mais para caracterizar ou predeterminar os objetos da investigação histórica, restringindo a análise aos temas e problemas da civilística atual; pelo contrário, deve ser utilizada da maneira proposta por Bretone (1998, p. 25), com função heurística e diagnóstica, atuando como instrumento para se compreender o passado jurídico em sua ligação com o plano metodológico. Adotar uma perspectiva historiográfica significa ressaltar o estranhamento entre o presente e o passado, quebrando a aparente evidência da linguagem mesmo diante da aparência de identidade e continuidade. Como explica Pietro Costa (2010, p. 77), tratar a História do Direito como labirinto, no qual devemos nos perder sem nenhum objetivo prático ou útil em mente, mas somente para alcançar essa experiência do estranhamento:

A historiografia é uma viagem no tempo: uma frágil e arriscada peregrinatio em mundos distantes e estranhos. Para que serve uma viagem historiográfica no tempo? São possíveis, como sabemos, diferentes respostas. Para o historicista, viajar no tempo significa traçar uma linha reta e segura entre o passado e o presente, submergir o presente no passado para entender as raízes do primeiro e a direção e sentido do segundo. Para o historicista a história serve. Viajar 
serve. É possível, porém, também uma atitude diferente: a atitude do viajante distraído e curioso. Para este viajante não existe uma linha segura e reta que liga o passado e o presente. [...] O sentido não está na ligação (por continuidade ou por analogia) com o presente, mas sim, na experiência de estranhamento. Claro, nada impede de constatar, de vez em quando, aproximações ou semelhanças com o nosso mundo: é de qualquer modo sempre a ele que pertencemos. O sentido da viagem é, porém, não mais a pesquisa do familiar, mas sim o confronto com o diferente.

Se Pietro Costa tem razão, e o interesse da História do Direito reside justamente em sua inutilidade, em construir-se como labirinto no interior do qual é possível nos perder, não há momento melhor para nós, historiadores, assumirmos também essa responsabilidade - que por tempo demais deixamos nas mãos dos civilistas. Afinal, o sentido da viagem no tempo realizada pela história não está na ligação, por continuidade ou analogia, do passado com o presente, mas na própria experiência de estranhamento, e no confronto com o diferente. A aposta da historiografia é evocar a existência de outros tempos e outras formas de vida, o que apenas se torna possível quando o passado se tornou, de fato, estranho, deixando de ter sentido para as necessidades do presente.

Hoje, quando dirigimos o olhar para os textos da tradição romanística, eles nos parecem relíquias antiquadas de um tempo felizmente perdido. A poeira dos séculos cobre as páginas do Digesto, e os seus últimos cultores sobreviventes mais parecem teimosos sacerdotes de uma religião já extinta, na insensata missão de anunciar a velha Palavra a ouvidos moucos de ímpios civilistas. Se olharmos para o direito romano dessa perspectiva, podemos confirmar que ele não serve para nada; mas poderíamos acrescentar, novamente com Costa (2010, p. 78), que é justamente a sua inutilidade que o torna indispensável. 


\section{Referências}

BRETONE, Mario. História do Direito Romano. Tradução Isabel Teresa Santos e Hossein Seddighzadeh Shooja. Lisboa: Editorial Estampa, 1998.

COSTA, Pietro. Para que serve a História do Direito? Um Humilde Elogio da Inutilidade. Soberania, representação, democracia: ensaios de história do pensamento jurídico. Tradução Ricardo Marcelo Fonseca. Curitiba: Juruá, 2010. p. 63-80.

GROSSI, Paolo. A formação do jurista e a exigência de uma reflexão epistemológica inovadora. História da propriedade e outros ensaios. Tradução Luiz Ernani Fritoli e Ricardo Marcelo Fonseca. São Paulo: Renovar, 2006. p. 85-121.

GROSSI, Paolo. L'Europa del diritto. 5. ed. Bari: Laterza, 2009. GROSSI, Paolo. L'Ordine giuridico medievale. 6. ed. Roma-Bari: Laterza, 2011.

HESPANHA, António Manuel. Cultura jurídica européia: síntese de um milênio. Florianópolis: Fundação Boiteux, 2005.

KANT, Immanuel. Crítica da razão pura. Tradução Valerio Rohden e Udo Baldur Moosburger. São Paulo: Nova Cultural, 1999.

LARENZ, Karl. Metodologia da ciência do direito. Tradução José

Lamego. 5. ed. Lisboa: Fundação Calouste Gulbenkian, 1983.

MOREIRA ALVES, José Carlos. Estudos de direito romano. Brasília, DF: Senado Federal, 2009.

SAVIGNY, Friederich Carl. Traité de la possession en droit romain.

Tradução Henri Staedtler. 2. ed. Paris: A. Durand \& Pedone Lauriel, Libraires-éditeurs, 1870.

SAVIGNY, Friederich Carl. Sistema del derecho romano actual. Tradução Jacinto Mesía y Manuel Poley. Madrid: F. Góngora y Compañía Editores, 1878. 
SCHIAVONE, Aldo. Ius: l'invenzione del diritto in occidente. Torino: Giulio Einaudi Editore, 2005a.

SCHIAVONE, Aldo. Uma história rompida: Roma Antiga e Ocidente Moderno. Tradução Fábio Duarte Joly. São Paulo: Editora da Universidade de São Paulo, 2005b.

VILLEY, Michel. Direito romano. Tradução Fernando Couto. Porto: Rés Editora, 1992.

WIEACKER, Franz. História do direito privado moderno. Tradução António Manuel Hespanha. 3. ed. Lisboa: Fundação Calouste Gulbenkian, 2004.

Walter Guandalini Junior é mestre e Doutor em Direito do Estado pela Universidade Federal do Paraná. Professor Adjunto na Universidade Federal do Paraná (Direito Romano). Membro do Núcleo de Pesquisa Direito, História e Subjetividade do Instituto Brasileiro de História do Direito e do Instituto LatinoAmericano de Historia del Derecho. Advogado da Companhia Paranaense de Energia.

E-mail: prof.walter.g@gmail.com

Endereço profissional: Universidade Federal do Paraná, Departamento de Direito Privado - Praça Santos Andrade - Centro. CEP: 80020300 - Curitiba, PR - Brasil. 
